Nota del editor: Este artículo es una reedición modificada de Fundamentos neurobiológicos para la práctica de EMDR, de U. Bergmann, 2012, New York, NY: Springer Publishing. Copyright 2012 de Springer Publishing. Reeditado con permiso.

\title{
La investigación de la conciencia: Una introducción a los fundamentos de la neurobiología del EMDR
}

\author{
Uri Bergmann \\ Commack, Nueva York
}

\begin{abstract}
La mente humana es difícil de investigar, pero los fundamentos biológicos de la mente, sobre todo de la conciencia, generalmente conllevan una mayor complejidad. En este artículo, extraído del libro Fundamentos neurobiológicos para la práctica de EMDR (Bergmann, 2012), introducimos y delineamos aspectos de la conciencia, el procesamiento de información y su relación con la terapia de desensibilización y reprocesamiento por movimientos oculares (EMDR). Examinamos la conciencia en relación a tres características: la unidad de percepción y función, la subjetividad y la predicción. Examinamos la relación de estas características con EMDR.
\end{abstract}

Palabras clave: conciencia; procesamiento de información; predicción; EMDR

$\mathbf{E}$ 1 material de este artículo es un extracto del libro Fundamentos neurobiológicos para la práctica de EMDR. El libro presenta la investigación más actual relacionada con las bases neurales de la conciencia y el EMDR en relación al apego, el estrés traumático y la disociación. Es el primer libro que integra completamente los nuevos hallazgos sobre el procesamiento de información, la conciencia, los trastornos traumáticos del procesamiento de información, el trauma crónico y cómo compromete al sistema autoinmune y las implicaciones de estos datos sobre el modelo de procesamiento adaptativo de la información (PAI) y el tratamiento EMDR.

El libro examina el procesamiento de información online/vigilia, incluyendo sensación, percepción, integración somatosensorial, cognición, aprendizaje, memoria, lenguaje y motricidad, así como el procesamiento de información offline/sueño, como el sueño de ondas lentas y el procesamiento cognitivo de la memoria y el sueño REM/onírico y su función sobre el procesamiento de la memoria semántica y emocional. El texto también trata sobre los trastornos de la conciencia, incluyendo el estado de coma, la anestesia y otros trastornos neurológicos, con atención especial a los trastornos del tipo I, TEPT, TEPT complejo/trastornos disociativos y trastornos de la personalidad. Profundiza en el trauma complejo y la función autoinmune, especialmente en relación a los síntomas sin explicación médica y los examina desde la perspectiva de los problemas autoinmunes resultantes del inusual perfil neuroendocrino de aquellos que padecen TEPT. La sección final integra todo el material para ilustrar las premisas del modelo PAI y la implicación de este material en relación con el tratamiento actual con EMDR, así como las técnicas que lo hacen más robusto.

This article originally appeared as Bergmann, U. (2012). Consciousness Examined: An Introduction to the Foundations of Neurobiology for EMDR. Journal of EMDR Practice and Research, 6(3), 87-91. Translated by Miriam Ramos Morrison. 


\section{Conciencia}

La mente humana es difícil de investigar, pero los fundamentos biológicos de la mente, especialmente los de la conciencia, generalmente conllevan una mayor complejidad. Antonio Damasio (1999) indica que si aclarar la naturaleza de la mente es la última frontera de las ciencias de la vida, a menudo la conciencia parece ser el último misterio en la iluminación de la mente. Señala,

El asunto de la mente, en general, y de la conciencia en particular, permite a los humanos activar al mäximo su deseo de entendimiento y su anhelo por maravillarse con su propia naturaleza que Aristóteles reconoció como tan específicamente humano. ¿Qué podría ser más difícil de saber que saber cómo sabemos? ¿Qué podría ser más vertiginoso que darse cuenta de que el tener conciencia es lo que hace posible e incluso inevitable nuestras preguntas sobre la conciencia? (p. 4)

Haciéndose eco de este sentimiento, Alan Hobson (2009) opina que "la conciencia, nos sentimos aliviados de admitir, finalmente es un auténtico tema de investigación. Demos el primer paso obvio y enseñémosla a estudiarse a sí misma” (p. xi).

Para Rodolfo Llinás (2001), la conciencia es una función de lo mental, lo que le lleva a preguntarse,

¿Por qué los procesos de la mente son tan misteriosos para nosotros? ¿Por qué siempre ha sido así? Los procesos que generan estados tales como el pensamiento, la conciencia y los sueños nos son extraños, imagino, porque siempre parecen generarse sin relación aparente con el mundo exterior. Parecen impalpablemente internos. (p. 4)

De forma similar, Alan Hobson (2009) observa,

El cerebro aún tiende a mantener la mayor parte de su actividad fuera de la conciencia, pero lo que excluye o admite se rige más por las reglas de la activación, la neuromodulación y los portales de entrada-salida que por el predominio de la represión. Ahora vemos el inconsciente como un sistema de consulta útil para el cerebro consciente en lugar de una fuente en ebullición de demonios dedicados a alterar la conciencia. La conciencia misma es, por lo tanto, una herramienta para la investigación de sí misma, así como para el estudio de esa parte del inconsciente que está reprimida de forma dinámica. (p. xi)

En sus escritos, Sigmund Freud articuló sus ideas a través de los conceptos organizadores del "yo" y el "objeto". Para Freud, las personas que interactúan con el yo eran los objetos de las impulsos y los deseos del yo. Irónicamente, los neurocientíficos de hoy en día tienden a ver la conciencia, desde sus niveles más básicos a su máxima complejidad, como la función neural integrada que reúne al objeto y al yo.

En consecuencia, Damasio (1999) opina,

En su nivel más básico y elemental, la conciencia nos permite reconocer una necesidad irresistible de seguir con vida y experimentar una preocupación por el yo. En su nivel más profundo y elaborado, la conciencia nos ayuda a desarrollar una preocupación por otros seres y mejorar el arte de la vida. (p. 5)

La evolución, a lo largo de estos millones de años, ha dado lugar a nuestro complejo cerebro y, de alguna manera, a través de las interacciones entre sus 100 billones de neuronas, conectadas por trillones de sinapsis, surge nuestra experiencia consciente del mundo y de nosotros mismos.

Nos guste o no, la conciencia es la función biológica fundamental que nos permite conocer la tristeza y la alegría, el sufrimiento y el placer, la vergüenza y el orgullo y el dolor y el reencuentro. Damasio (1999) reflexiona: "No culpes a Eva por saber; culpa a la conciencia y también dale las gracias" (p. 4).

\section{El misterio de la conciencia}

Entonces, ¿cómo puede la actividad interna del cerebro representar realmente al mundo exterior? ¿Cómo nos permite interactuar con el mundo externo e internamente con el nuestro?¿Cómo hace para diferenciar la realidad externa de la interna? Si la conciencia es intrínseca a la función cerebral, ¿hay entonces algún lugar en el cerebro que podamos aislar y considerar el asiento de la conciencia? ¿O tendremos que buscar más bien una red neural distribuida a gran escala, por todo el cerebro?

Una manera alternativa de explorar estos misterios es preguntar cómo el cerebro media en el procesamiento de información, lo que nos lleva al estudio de las neuronas individuales y su relación con los sistemas neurales. Las neuronas individuales funcionan unidas en grupos especializados o sistemas, cada uno de los cuales realiza una función especial. La neurociencia de los sistemas es el estudio de estos sistemas neurales, que incluyen aquellos implicados en la visión, la memoria, el lenguaje, la emoción y la función motora. En consecuencia, estos sistemas poseen propiedades en común, particularmente en el hecho de que todos procesan información de alto nivel relacionada con nuestro entorno y nuestras necesidades biológicas. 
Por ello, el estudio de la neurociencia de los sistemas enfatiza de manera primordial la identificación de las estructuras neurales y los eventos asociados con los pasos jerárquicos en el procesamiento de la información. Por lo tanto, ahora podemos refinar aún más nuestras preguntas y plantear lo siguiente: ¿Cómo se codifica la información (sensación)? ¿Cómo se interpreta para otorgarle significado (percepción)? ¿Cómo se modifica o almacena (aprendizaje y memoria)? ¿Cómo se utiliza para predecir el estado futuro del entorno y las consecuencias de la acción (toma de decisiones/ emoción)? ¿Cómo se utiliza para guiar la conducta (control motor) y para comunicar (lenguaje)?

\section{Conciencia y evolución}

Eric Kandel (2006) sostiene que cada revolución tiene sus orígenes en el pasado y que la revolución que ha culminado en la nueva ciencia de la mente no es una excepción. Aunque el papel central de la biología en el estudio de los procesos mentales o psicológicos era algo nuevo, la profunda capacidad de la biología para influenciar la manera en la que nos vemos a nosotros mismos no lo era. A mediados del siglo XIX, Charles Darwin sostenía que no habíamos sido creados de manera única sino que más bien habíamos evolucionado gradualmente de ancestros que eran animales inferiores. Propuso la idea, incluso más atrevida, de que la fuerza impulsora de la evolución no era consciente, inteligente ni divina, sino un proceso "ciego" de selección natural, un proceso de clasificación completamente mecánico de ensayo y error aleatorio (una modificación, tinkering en inglés) basado en variaciones hereditarias.

Las ideas de Darwin desafiaron las enseñanzas de la mayoría de las religiones. Dado que el propósito original de la biología había sido explicar el diseño divino de la naturaleza, sus ideas destrozaron el vínculo histórico entre la religión y la biología. Eric Kandel (2006) señala que, para algunos, la neurobiología de la mente es potencialmente más perturbadora porque sugiere que no sólo el cuerpo sino también la mente y las moléculas específicas que subyacen a nuestros procesos mentales más elevados, de conciencia del yo y de los otros y del pasado y el futuro, han evolucionado desde nuestros ancestros animales. No obstante, como veremos, esta perspectiva evolutiva ha facilitado nuestra comprensión en profundidad, guiándonos hacia el estudio de los sistemas nerviosos de los animales inferiores, como el molusco Aplysia. Por medio del estudio del aprendizaje, tal como la habituación, la sensibilización y el condicionamiento en este animal, los patrones neurales de aprendizaje y memoria fueron codificados por primera vez de manera clara y consistente. Con el tiempo y con el aumento de la sofisticación tecnológica, se descubrieron patrones neurales similares en el funcionamiento humano, con lo cual se confirmaron tanto las ideas de conectividad evolutiva de Darwin como las teorías de plasticidad sináptica de Ramón y Cajal.

\section{Características de la conciencia}

En los últimos 20 años, la conciencia también ha sido descrita e investigada en relación a tres características: unidad, subjetividad y predicción.

Unidad de la conciencia. La naturaleza unitaria de la conciencia hace referencia al hecho de que nuestras experiencias nos llegan como un todo unificado. Todas las diversas modalidades sensoriales (esto es, color, forma, profundidad, sonido, sabor y olor) se integran y se unen en una experiencia consciente coherente.

Subjetividad. Lo anterior habla de la información que nos llega del mundo exterior. Sin embargo, lo mismo también es cierto de nuestras experiencias propioceptivas internas, de manera que modalidades tales como asociaciones, recuerdos y emociones están igualmente integradas y unidas con nuestras experiencias sensoriales para producir una experiencia subjetiva coherente.

Predicción. Con respecto la predicción, Llinás (2001) ha señalado que la conciencia, o el estado de mentalidad, que puede o no representar la realidad externa (estados subjetivos, imaginación o ensoñación), ha evolucionado como el aparato orientado hacia los objetivos que implementa interacciones predichas/intencionales entre un organismo vivo y su entorno. Dichas transacciones, para tener éxito, requieren un instrumento heredado y previamente cableado que genera una imagen subjetiva interna del mundo exterior que puede compararse con la información objetiva transducida por los sentidos desde el entorno externo. (p. 3)

Dado que esta comparación funcional entre las imágenes sensoriomotoras generadas internamente y la información sensorial en tiempo real del entorno inmediato del organismo se define como percepción, entonces la función de los mecanismos subyacentes a la percepción es mediar en la predicción, esto es, "la expectativa útil de los eventos que están por llegar” (p. 3). Desde una perspectiva evolutiva/de supervivencia, que es la fuerza impulsora que tienen en común todas las especies, la predicción, con su esencia de orientación hacia los objetivos, es el meollo de la función 
cerebral y la conciencia. Obviamente, la capacidad de predicción es fundamental en el reino animal; la vida de cualquier criatura depende de ello. Aun así, el mecanismo de predicción es mucho más ubicuo en el control cerebral de las funciones corporales.

\section{La predicción en acción}

Consideremos el simple acto de estirar la mano para sacar un envase de leche del refrigerador. Sin pensar mucho nuestras acciones, hemos de poder predecir el peso del envase, si se nos va a escurrir, lo lleno que está y, finalmente, el equilibrio compensatorio que debemos aplicar para realizar una trayectoria suave y con éxito de los contenidos del envase hasta nuestro vaso.

La capacidad predictiva del cerebro también puede generarse en ausencia de la conciencia. Como ejemplo, ¿alguna vez te has encontrado parpadeando justo antes de que se te meta un bicho en el ojo? No has podido observar al bicho, al menos a nivel consciente, pero sin embargo, de alguna manera, has podido predecir el evento y has parpadeado adecuadamente para prevenir que entrase en el ojo. La predicción es la esencia de este mecanismo protector (Llinás, 2001).

La predicción, continuamente operativa a nivel consciente, inconsciente y reflejo, es generalizable a través de la mayoría de los niveles de funcionamiento cerebral. Como veremos más adelante, para que el sistema nervioso pueda predecir, debe realizar una comparación rápida entre las propiedades sensoriales/input del mundo externo y una representación del mundo interna/subjetiva independiente. En humanos (y en ciertos animales), esta representación interna está determinada por experiencias, asociaciones, recuerdos y emociones sensoriomotrices. Este equilibrio precario entre objetividad externa y subjetividad interna y las predicciones que genera sobre nosotros mismos, nuestro entorno y aquellos que nos rodean es la esencia de nuestro conocimiento, creatividad, alegrías y penas y la calidad de nuestras relaciones.

\section{Conciencia y EMDR}

La conciencia y el EMDR han estado íntimamente relacionados, aunque bajo un nombre diferente. Mientras que el campo de la neurobiología ha utilizado el término conciencia para referirse a los procesos de sensación, percepción, aprendizaje, cognición, emoción, integración somato-sensorial y memoria; la disciplina de la psicología ha optado por utilizar el término procesamiento de información. En consecuencia, se utilizarán de manera intercambiable. Si tendemos a favorecer el término conciencia en este libro, es sólo porque se siente más humano.

A lo largo de los últimos 20 años, el método EMDR se ha convertido en un abordaje terapéutico guiado por el modelo de procesamiento adaptativo de la información (PAI) (Shapiro, 2001). En 1990, el cambio de nombre de desensibilización por movimientos oculares a desensibilización y reprocesamiento por movimientos oculares anunció un cambio de orientación: de la formulación conductista inicial de desensibilización simple de la ansiedad a un paradigma de procesamiento de información más integrado. Esta evolución marcó el comienzo del modelo de procesamiento acelerado de información, lo que ilustra una comprensión con base clínica de los principios subyacentes que rigen la percepción y la integración de nueva información dentro de los marcos de trabajo cognitivos, de memoria y emocionales (Shapiro, 1995). En 2001, esta continua evolución nos trajo el citado modelo del procesamiento adaptativo de información. Respecto a estos modelos, Francine Shapiro (2001) ha argumentado que "su utilidad radica en su capacidad no sólo de explicar, sino de predecir resultados clínicos” (p. 14).

\section{Predicción y EMDR}

Como veremos, la predicción y el procesamiento de información también tienen un lugar importante en el tratamiento EMDR, dada la centralidad de las cogniciones positivas y negativas, las cuales articulan predicciones con respecto al entorno, los otros/objetos y el yo. A la vista de ello, una cognición negativa distorsionada es claramente sintomática de un procesamiento de información predictivo no adaptativo.

Como otras especies animales, procesamos información para generar predicciones sobre el entorno (¿seguro, peligroso, venenoso, nutritivo?) y sobre aquellos que nos rodean (¿seguros, confiables, peligrosos?). Sin embargo, los humanos también generamos predicciones sobre nosotros mismos (¿bueno, malo, capaz, incapaz?).

Todas estas permutaciones de la conciencia y el procesamiento de la información, los sistemas neurales oscilatorios, que se corresponden con las diversas modalidades sensoriales externas y propioceptivas internas, están sincronizadas con respecto a sus oscilaciones para producir experiencias conscientes coherentes (unificadas) - procesos denominados enlace neural y vinculación temporal.

\section{El progreso de la ciencia}

Reflexionando sobre lo anterior, se hace evidente que la comprensión de la mente humana en términos 
biológicos ha surgido como uno de los retos más importantes para la ciencia en el siglo XXI. Nuestro objetivo en esta gesta es comprender los fundamentos biológicos de la integración de la sensación, la percepción, la cognición, el aprendizaje, la memoria, la emoción y los sentidos.

El progreso realizado por los investigadores-el campo de la neurociencia, impensable siquiera hace unas pocas décadas, ha hecho posible nuestro conocimiento actual. El descubrimiento de la estructura del ADN en 1953 revolucionó la biología, aportando una infraestructura fundamental para entender los mecanismos que subyacen a la capacidad de los genes de controlar el funcionamiento de las células. Este avance dio lugar a una comprensión básica de la regulación de los genes y la función celular relacionada con los genes, impulsando el entendimiento de la ciencia de la biología a un nivel que rivaliza con el de la física y la química.

Imbuida con este conocimiento, la biología dirigió su atención hacia su objetivo más alto, la comprensión de la naturaleza biológica de la mente humana. Este esfuerzo, considerado tiempo atrás como pre-científico e imposible, ha adquirido gran impulso y crecimiento. Irónicamente, estas nuevas revelaciones no llegaron desde las disciplinas que tradicionalmente se ocupaban de la mente, desde la filosofia o la psicología. En cambio, se desarrollaron a partir de la fusión de estas disciplinas con la biología del cerebro, una nueva síntesis que ha sido posible gracias a los notables logros en el campo de la biología molecular. El resultado ha sido una nueva ciencia de la mente, una ciencia que ha empleado el poder de la biología molecular para examinar los grandes misterios de la vida que quedan por resolver.

\section{Mente y cerebro}

Esta nueva ciencia se basa en cinco principios. Primero, la mente y el cerebro son inseparables. El cerebro es un órgano biológico multifacético con amplias habilidades computacionales que construye nuestras experiencias sensoriales, regula nuestros pensamientos y emociones y media en nuestras acciones. Nuestro cerebro es responsable no sólo de conductas motoras como correr y comer sino también de actos complejos y multifacéticos considerados la esencia del ser humano, como pensar, hablar y crear obras de arte.

Segundo, cada función mental en el cerebro, desde los reflejos más simples a los actos más creativos del lenguaje, la música y el arte, se lleva a cabo mediante circuitos neurales especializados en las diferentes regiones del cerebro.
Tercero, todos estos circuitos están compuestos de las mismas unidades elementales de señalización, la neurona. Cuarto, estos circuitos neurales utilizan moléculas específicas para generar señales dentro de y entre las células nerviosas. Finalmente, las moléculas específicas de señalización se han conservado y mantenido a lo largo de millones de años de evolución. Algunas de ellas están presentes en las células de nuestros ancestros más antiguos y se pueden encontrar hoy en día en nuestros parientes evolutivos más distantes y primitivos.

Por tanto, de estos nuevos conocimientos relacionados con la ciencia de la mente no sólo ganamos conciencia de nosotros mismos - cómo percibimos, aprendemos, recordamos, sentimos y actuamos - sino también un nuevo punto de vista sobre nosotros mismos dentro del contexto de la evolución biológica. En consecuencia, esto nos permite apreciar que la mente humana evolucionó a partir de moléculas utilizadas por nuestros antepasados más primitivos y que la extraordinaria conservación de los mecanismos moleculares que regulan los diversos procesos de la vida también es aplicable a nuestra vida mental.

De igual modo, la búsqueda de los mecanismos de acción del EMDR comenzó a principios de la década de 1990, inicialmente de manera lenta y tentativa. Al entrar en el nuevo milenio, el ritmo se aceleró. Los modelos teóricos basados en los hallazgos empíricos de la base de estudios neurobiológicas relacionados, se hicieron más detallados y prevalentes. Paralelamente, los estudios neurobiológicos se expandieron cada vez más, utilizando análisis psicofisiológicos y de neuroimagen del tratamiento EMDR.

En la última década, se hecho cada vez más evidente que las personas que carecen de experiencia científica están tan entusiasmadas por aprender estos nuevos conocimientos relacionados con la ciencia de la mente y la conciencia como lo están los científicos por explicarlos.

\section{El crecimiento científico de EMDR}

Puede verse un fenómeno similar en el mundo de EMDR. Al principio, pocos estaban interesados en la neurobiología de EMDR. En un día bueno, una charla que especulaba sobre los mecanismos neurales del EMDR podía atraer a 30 personas. Como en otros aspectos de la neurociencia, este interés se ha disparado. Hoy en día, cientos de personas atienden talleres de EMDR a nivel mundial, enfocados exclusivamente en el tema de la neurobiología del EMDR. Por tanto, estos acontecimientos han puesto de manifiesto que los no científicos están dispuestos a hacer el esfuerzo de comprender las cuestiones fundamentales de la 
ciencia del cerebro si los científicos están dispuestos a hacer el esfuerzo de explicarlas.

Por lo tanto, la conciencia y el EMDR están inextricablemente entrelazados, dándonos un paradigma de procesamiento de información que proporciona un enfoque integrado que puede incorporar e interpretar aspectos clave de diversas modalidades tales como la psicodinámica, la conductual, la cognitiva, la Gestalt, los estados del yo y las terapias orientadas al cuerpo. Si la neurobiología de la conciencia nos permite la comprensión de la interrelación neural entre yo y el objeto, el EMDR nos ha dado tanto herramientas como misterios que resolver a la hora de reparar el yo y su relación con los objetos.

\section{Referencias}

Bergmann, U. (2012). Neurobiological foundations for EMDR practice. New York, NY: Springer Publishing.

Damasio, A. R. (1999). The feeling of what happens. New York, NY: Harcourt Brace.
Hobson, A. (2009). Prologue. En S. Laureys \& G. Tononi (Eds.), The neurology of consciousness (pp. xi-xii). New York, NY: Elsevier, Academic Press.

Kandel, E. R. (2006). In search of memory: The emergence of a new science of mind. New York, NY: W. W. Norton.

Llinas, R. R. (2001). I of the vortex: From neurons to self. Cambridge, MA: The MIT Press.

Ramon y Cajal, S. (1899). Textura del systemo nervioso del hombre y de los vertebrados [Texture of the nervous system of man and vertebrates]. Madrid, Spain: Moya.

Shapiro, F. (1995). Eye movement desensitization and reprocessing: Basic principles, protocols, and procedures ( $\left.1^{\mathrm{a}} \mathrm{ed}.\right)$. New York, NY: Guilford Press.

Shapiro, F. (2001). Eye movement desensitization and reprocessing: Basic principles, protocols, and procedures ( $2^{\mathrm{a}} \mathrm{ed}$.). New York, NY: Guilford Press.

La correspondencia relacionada con este artículo debe dirigirse a Uri Bergmann, 366 Veterans Memorial Highway, Suite 1A, Commack, NY 11725. E-mail: ubergmann@att.net 